\title{
PHAVER syndrome
}

INSERM

\section{Source}

INSERM. (1999). Orphanet: an online rare disease and orphan drug data base. PHAVER syndrome. ORPHA:2876

Phaver syndrome is a very rare syndrome characterized by the association of limb Pterygia, Heart anomalies, Autosomal recessive inheritance, Vertebral defects, Ear anomalies and Radial defects. 